\title{
Tope Omoniyi
}

\section{A borderlands' perspective of language and globalization}

\begin{abstract}
My primary objective in this article is to explore what new meaning borderlands research can bring to our understanding of globalization as it is presently framed in sociolinguistic scholarship. As a site of negotiations and transactions in international goods and services in the official and non-official realms they present us with a microcosm of globalised networks. The specific territoriality of a borderland illustrates localization which Waters (2001: 5) says implies "a reflexive reconstruction of community in the face of the dehumanizing implications of rationalizing and commodifying", a referencing against global scapes. I also present and explore continentalization as an African social process modeled on globalization by looking at the impact that Nollywood as a cultural industry is having across national boundaries.
\end{abstract}

Keywords: conceptual borders, Africa, globalization, continentalization

Tope Omoniyi: The University of Roehampton. E-mail: T.Omoniyi@roehampton.ac.uk

It is not that I believe that we can understand contemporary globalization processes only by looking at language and communication; it is that I firmly believe that we cannot understand them without attention to language and communication. (Blommaert 2008: 24)

\section{Introduction}

Borderlands have been associated with a kind of sociolinguistics characterized by relations of spatial adjacency between two polities and the communicative dynamics of the population networks that inhabit them complete with intensified interstate, intercommunity and interpersonal relationships. They have local, international, and potentially global dimensions. Coupland (2003: 466) noted that researching many domains of social life "requires us to attend to global as well as local bases of social organization" for none of the practices intrinsic to a borderland community can be divorced from the history of the community and part of that history connects to far-flung times and spaces. In so many cases 
around the world that history is bound up with factors recognized today as crucial to the theorizing of globalization. It is no doubt a complex social process in which time and space are compressed (Robertson 1992: 8), and one characterized by the "intensification of world-wide social relations which link distant localities ..." (Giddens 1990: 64), or indeed as Waters says, it is "the autonomization of local lifeworlds" (2001: 5). Similarly, borderlands are at one and the same time a conflation of contiguous nation state spaces governed by global etiquettes of coexistence, as well as a meeting point or bisection of local traditions that pre-date the nation-states are complex.

The extensive studies of Latin American borderlands from the 1970s onwards (see Hensey [1972] and [1982] on the Brazil-Uruguay border for instance), European border studies championed by Raimondo Strassoldo and the more recent European Union FP5 EU Border Identities project led by Ulrike Meinhof and her team on the EU Framework 5 European Borders project (2000-2003), and those of African borderlands led by Asiwaju in the 1980s have been done from a mix of disciplinary traditions including linguistics, economics, sociology and history (see also Omoniyi 2004; Omoniyi and Salami 2004). Even so, they were mostly confined to their local bases without a perspective on how developments elsewhere around the world might be remotely or directly responsible for the observed practices and trends and vice-versa. This is most visible in language contact borderlands where the exchange of goods and services involve a mix of local and global communicative regimes. Martinez's (2009) study of medical interpreting in healthcare delivery in the Lower Rio Grande Valley on the US-Mexico border reveals that "the act of language brokering is grounded in different role expectations" which include the neutral conduit, the patient advocate, and the institutional gatekeeper roles.

Arguably the debates in Asiwaju's African borderlands studies linked as they were to colonial realities may be said to demonstrate another dimension of such local and global interconnections. I see all these studies not as separate but interconnected enquiries with each one facilitating a more complete understanding of the others. The multidisciplinary edited borderlands volume (Asiwaju and Adeniyi 1989) even included a chapter on fossil lives and biodiversity, themes that became central to Skutnabb-Kangas's scholarship in minority language preservation and linked to biodiversity in the 2000s. In my view, these reference the four tentative concepts to which Coupland hinges minority language research under globalization: community interdependence, the compression of time and space, disembedding and commodification (Coupland 2003: 467). Inasmuch as borderlands scholarship entails a history of struggle, resistance and conflict between peoples, Europeans in the Americas, Africa or Asia, inequality of all sorts, language use and identity in communities bisected by a boundary line or ones 
that have contiguously sprung up as a consequence of the setting up of border posts between two countries, language issues of borderlands have both local and global dimensions. Within such a sociolinguistics I shall attempt to discuss the following:

1. Colonisation and the birth of global languages

2. Migration and its sociolinguistic implications

3. Borderlands as zones of continuity and transnational flows (cf. zones of transition)

4. Continentalization as an approach to globalization

On 1 April 2009, over 2000 protesters from different parts of the world, especially European countries converged on The City, the financial hub in London. It was the eve of the G20 Summit. It was a protest against capitalism, corporations, recession and the Greenhouse Effect. G20 meetings in a sense are a part of the complex process of globalization, a manifestation of the Collective Global Destiny. Apart from the more obvious presence of the official languages of these countries at the meeting, there were also the varieties of English indigenous to the countries from which the protesters derived. Globalization facilitates the crossing of borders and the dynamism of shares in the linguistic stock market. After all, a discourse accompanies the US $\$ 300$ billion foreign direct investment (FDI) estimated by the World Bank to cross borders from the developed economies to the developing economies including immigrants repatriating assistance to their homelands. A number of concepts are pivotal to our discussion in this chapter and definitions are a good place to start.

\section{Definitions: boundaries, borders, borderlands}

One of the incipient problems in borderlands research is that terms are often used loosely, sometimes as synonyms, although in reality they differ as theoretical concepts. Thus it is useful that at the outset we proffer definitions for the key concepts that will frame the discussion in this article.

Boundaries are geopolitical demarcations that separate and enclose spaces occupied by sovereign states. These spaces are defined within the precise geographic coordinate system of longitudes and latitudes. So for example, Zimbabwe is the country that lies between Longitude $31^{\circ} 02^{\prime} \mathrm{E}$ and Latitude $17^{\circ} 43^{\prime} \mathrm{S}$. The definiteness or finiteness of national space is conveyed by Momoh's (1989: 55) definition of a boundary as representing "the determinate physical end of a frontier for the moment". Ironically, in postcolonial Africa, these frontiers are indeed ethnic 
hinterlands for the 103 ethnic groups bisected by colonial boundaries (Asiwaju 1985). Thus there is in the idea of nation-state boundaries already a conflict of local, national and international realities; contrasting frontier and hinterland roles rolled into one physical space amount in a sense to a schizophrenic existence. The following international boundaries are straddled by the ethnic groups indicated in brackets among others:

- Angola - Namibia [Ovambo]

- Benin - Nigeria [Gun/Egun, Yoruba, Borgu]

- Cameroon - Nigeria [Kanembu, Shuwa Arabs, etc.]

- Cameroon - Congo [Bakwaele, Njem ... ]

- Chad - CAR [Azande]

- Ghana - Togo [Ewe, Ahufo, Moba]

But this phenomenon is not peculiar to Africa as these examples from other parts of the world show:

- Kosovo - Serbia [Serbians]

- India - Pakistan [Kashmirs]

- Pakistan - Afghanistan [Pashtuns]

- Romania - Hungary [Romanians]

- Georgia - Russia [Ossertians]

- Iraq - Turkey [Kurds - Kurdistan is split between five nations!]

All of these are similarly traceable to various colonial histories and manoeuvres, ancient and modern.

Borders are the immediate areas at which states separated by a boundary articulate and manage their individual sovereignties including officially designated border crossings, border posts, and other actual physical structures that mark the presence of the sovereign state. The immigration posts in Dover-Calais (UK and France), Cenad-Kiszombor (Romania and Hungary) and El Paso and Ciudad Juárez (USA and Mexico) illustrate this fact.

Borderlands, in contrast, refer to the communities and spaces directly impacted by the contiguity of two states - "the region or zone on both sides of given boundaries" of which there are three types: Zero, Minimal and Maximal (Momoh 1989). What are these?

- Maximal: cultural and linguistic affinities across the boundary line and are often "an expansive area of contact" (Momoh 1989: 52). Movement is unimpaired.

- Minimal: lack of cultural or ethnic affinity on opposite sides of a boundary and are on average $2-5$ kilometers in diameter.

- Zero: This entails a total blockade. North and South Korea. 
I shall add to these the notion of conceptual boundaries, conceptual borders and conceptual borderlands which derive from the above. Essentially these are mental mappings that we construct and invoke in managing relationships with individuals, groups and institutions. They have no real physical markers of contiguity as we experience with reference to the land between contiguous countries, yet we are aware of their representation of imagined divisions and contiguities as well as of the norms and rituals involved in negotiating them. Here there are slight variations depending largely on the history that informs the specifically imagined phenomenon. For example, taking a cross-Atlantic flight from London Heathrow to Chicago O'Hare, one might not be conscious of when the aircraft enters the airspace of the United States, but the encounter with US immigration officers and Homeland Security personnel at O'Hare is the culmination of a period of preparation beginning with visa applications back in London and the completion of Landing cards and Customs and Excise cards on board the flight shortly before landing. The transaction that takes place at that final point includes a declaration, clearance and admission all three of which are crucial to the fulfillment of a traveler's objective of going to the US in the first place. The crossing into US airspace is a boundary crossing experience, the immigration counters at the airport where individuals are processed represent the border post but the twin post is at the departure airport and physically invisible but imagined. These experiences form part of an "entering the US ritual". The conceptual borderland encompasses all of the spaces and people involved in executing the movement.

A slightly different example of conceptual boundaries is that which we create or invoke in anticipation of encounters with people often for the first time in which we consider what we can or will talk to them about. If we are meeting someone who has recently been bereaved, jokes about death automatically become taboo. Similarly, if we are meeting a friend of a friend for the first time having only been introduced by a mutual friend via email, we pre-map the discursive terrain that the encounter could transverse and with varying degrees of apprehension. Also, I shall put into this general category, e-boundaries (imagined separators between different nodes such as national ones, for example ".co.uk" [United Kingdom] and “.co.cn" [China], or between ".uk.gov.org” [government] and “.ac.uk" [public academic institution]), network, e-borders (internet police, moderators of web-forums who screen content) and e-borderlands (Omoniyi 2007, 2013). The application of Momoh's three-way classification to conceptual borderlands is rather straightforward and determined by an evaluation of the different relationships and situations and the nature of histories and memories that culminate in the encounters.

The sociolinguistic concomitants of these delimiter concepts become obvious in the discursive contexts in which language strategies are deployed. Those who 
live a transnational existence facilitated by the nature of their careers move between, in and out of communicative cultures and constantly exchange one set of strategies for another as appropriate to the contexts in which they are operating at different points in time. From language choice to accent moderation, issues of convergence (or divergence), varying pragmatic repertoires from one intercultural context to another may be said to characterize the linguiscape, which complement Appadurai's (1996) concepts of cultural globalization, that is ideoscapes and mediascapes, the reality of a globalised world marked by human mobility and the mobility of ideas and communication. This understanding engineers our understanding of the difference between the McDonald chain advertisements of its culinary options in Muscat (Oman) and Reading (UK). Global intellectuals who take up visiting professorships or speak at international conferences virtually anywhere in the world negotiate the language demands of each of their ports of call.

In Africa, ethnonationalism has fuelled large scale intergroup distrusts and rivalry and played a role in the crisis in Liberia, Sierra Leone, Nigeria, Sudan, Congo, Angola and Rwanda. In the disturbances that preceded the Nigerian civil war, one of the myths of identification was the substitution of the liquid / $1 /$ for the roll / $\mathrm{r} /$ in Thro pence by some native speakers of Igbo. That substitution became an unofficial ethnolinguistic sieve employed by some Nigerian Federal Troops in identifying secessionist Biafrans. In other words, it was a profiling tool in a matter of life and death. Thus, while certain linguistic features and practices had potential to move beyond the local sphere, some were confined to the sphere and served essentialist and stereotypic purposes. This remains one of the undocumented atrocities of the thirty-month war by its chroniclers.

The civil war that decimated Rwanda's population in 1994 pitched its two main ethnic groups - Hutus and Tutsis - against each other. Historically, the Tutsis had migrated southwards from Ethiopia in the fifteenth century and established dominion over the Hutus. Both groups intermarried and lived together in one kingdom under a deified Tutsi king, as a Belgian suzerainty, League of Nations Class B Mandate and United Nations Trust Territory from 1916 to 1962. They split into two countries Rwanda and Burundi at independence in 1962. The Hutus were the dominant majority in Rwanda while the Tutsis were the dominant majority in Burundi. The languages known as Kinyarwanda in Rwanda and Kirundi in Burundi are mutually intelligible. This coupled with the history of large scale intermarriages suggest the existence of a maximal borderland between these countries. Particularly interesting is the role of language policy in making these borders zones of continuity. Kirundi and French are official languages in Burundi, while English, French and Kinyarwanda have that status in Rwanda (Gordon 2005). 


\section{Migration, sociolinguistics and borders}

Considering that mobility is one of the core ingredients of globalization, it stands to reason that the language dimensions of cross-border migration should be examined here. Kerswill (2006) differentiates between geographical diffusion which does not involve people movement and relocation diffusion which does. However, in his treatment of migration he also focused on non-contiguous spaces. My contention, however, is that Kerswill's physically non-contiguous spaces are perceivable as conceptually contiguous. This way of thinking allows us to establish a firmer link to language and globalization.

According to Churches' Commission for Migrants in Europe (CCME), there are two types of asylum countries: those host countries that provide opportunity to integrate locally "through access to land or the labor market" and those host countries in which refugees "remain confined to camps where they depend on assistance from the international community" (Passarelli and Peschke 2006). In the latter more than in the former, the linguistic challenge of forced migration strikes the refugees harshly. Campsite programs may create replicas of the ethnic communities of the homeland whereas refugees accessing the new labor market of an adopted temporary home are immediately confronted by communicative demands within a new sociolinguistic scale (Blommaert 2006). See Table 1.

Table 1: Global refugee trends in 2004

\begin{tabular}{lccc}
\hline \multicolumn{4}{c}{ Refugee population by UNHCR Bureau 2004 } \\
\hline UNHCR Bureau & Begin & End & Annual change \\
\hline Central Africa and Great Lakes & $1,257,900$ & $1,267,700$ & $0.8 \%$ \\
East and Horn of Africa & 768,100 & 770,500 & $0.3 \%$ \\
Southern Africa & 306,200 & 245,100 & $-20.0 \%$ \\
West Africa & 531,200 & 465,100 & $-12.4 \%$ \\
\hline Total Africa & $2,863,400$ & $2,748,400$ & $-4 \%$ \\
\hline CASWANAME & $2,827,300$ & $2,735,200$ & $-3.3 \%$ \\
Americas & 623,900 & 598,400 & $-4.1 \%$ \\
Asia and Pacific & 823,600 & 836,700 & $1.6 \%$ \\
\hline Europe & $2,454,800$ & $2,317,800$ & $-5.6 \%$ \\
\hline Total & $9,593,000$ & $9,236,500$ & $-3.7 \%$ \\
\hline
\end{tabular}

In sub-Saharan Africa, the density and diffusion of ethnolinguistic communities become subject to variation along refugee routes. 


\section{Borderlands as zones of continuity vis-à-vis transition}

The resulting notion of nation post-scramble and partition differs from Europe's conceptualization of nation in the post-enlightenment period. Consequently, African borderlands subvert agendas and asymmetries entrenched in colonial and globalization structures. This in turn disrupts the popular Anglophone versus Francophone binary opposition considered to be entrenched in a substantial part of postcolonial literature. In addition, it alters the conventionally assumed direction of flow of some consumables from North to South. I use the latter in place of the normative reference to "South-South" cooperation or collaboration which is itself a discourse engineered outside of Africa but about the continent. This inward looking stance ought to be institutionally recognized and explored in policy and planning as a viable alternative.

\subsection{Framing continuity}

The core argument underlying my discussion in this article is that in relation to the African experience and borne out by events in other parts of the world, for example, in Asia and Latin America, a sociolinguistics of colonization (Omoniyi 2010), that is, the language and linguistic relationship between individual colonizer and colonized states is aligned to a sociolinguistics of globalization (cf. Blommaert 2003), that is, the language-determined or language influenced global systems of flow of goods and services, a network of exchange.

In the relationships delineated above the nature of mediation and facilitation by language accounts for the disparity in the capital allocated to former colonial languages and Africa's indigenous languages and language varieties. In other words, any structural imbalances and asymmetries observable globally between nations are partially attributable to manipulation or deployment of language and linguistic resources. I shall use two contrasting cases to illustrate the connection between the sociolinguistics of colonization and the sociolinguistics of globalization: Southeast Asia and Sub-Saharan Africa. Let us go to Southeast Asia first.

World Bank statistics and differential classifications of countries in Southeast Asia in terms of development arguably reflect statuses of languages associated with the bordering economies, especially those which had shared the same colonial trajectory, like Singapore and Malaysia. The former is listed among the Newly Industrialized Economies while the latter is classified as a Middle In- 
come Economy. But Malaya had split upon independence from Britain in 1965 into two predominantly Chinese and Malay states, Singapore and Malaysia respectively. The boundary between the two at Woodlands-Johor Bahru also represents a cultural boundary between an Islamic Malaysia and secular Singapore. However, the community at this maximal borderland constitutes an interesting sociocultural network with relatives on both sides of the divide (see Omoniyi 2000).

The African illustrations of borders and globalization contrast in interesting ways with the picture that we gleaned for Southeast Asia earlier. As in Southeast Asia, the sociolinguistics of colonization contextualizes the relationships between indigenous African languages and former European colonial languages. Pan-Africanism had responded to colonization through resistance discourses in the mid-20th century and spread across Africa (see Mazrui and Mazrui 1998; Mazrui 2005; Wa Thiong'o 2005). In the post-colony, the transborder nature of a pan-African political tradition is evident in the wave of copycat military coup d'etats that gripped the continent. The fact that the continent also responded to democracy in much the same manner is confirmation that it could be subject to a singular process of transformation. That is the basis of my suggestion in this article that in the current dispensation, Pan-Africanism may be serving globalization today through cultural continentalization.

Continentalization as an alternative or complementary globalization paradigm is fashioned within the framework of resistance discourse because it undermines colonial boundaries which are not coterminous with the ethnic geography of the continent (see Gakwandi 1996: 188). We observe transcultural flows facilitated by African borders functioning as zones of continuity. Asiwaju (1985) identifies 103 ethnolinguistic groups that straddle colonial divides across the continent. It is a departure from the binary paradigm of Western Centre and their African peripheries to the recognition of multiple centers. See Figure 1.

Inhabitants of the Nigeria-Benin borderland had reportedly claimed that "We regard the boundary as separating the English and the French not the Yoruba" (see Prescott 1965: 103). The same claim, which was repeated by the Oniko (king) of Idiroko in 1991 (see Omoniyi 2004), captures the perception of borderlands here as zones of continuity. More importantly, it separates the state as a quasilegal entity and identity from the borderland community and its people. This indigenous African perspective of boundaries allows us to construct continentalization as an analytical framework since the borderlands link all of SubSaharan Africa up into one interconnected unit. This involves a groundswell of continent-wide ramifying sociocultural practices, including multilingualism, and multiple centers. Continentalization is a form of bottom-up globalization in Africa controlled by localized social agents within the continent (e.g. film industries like 


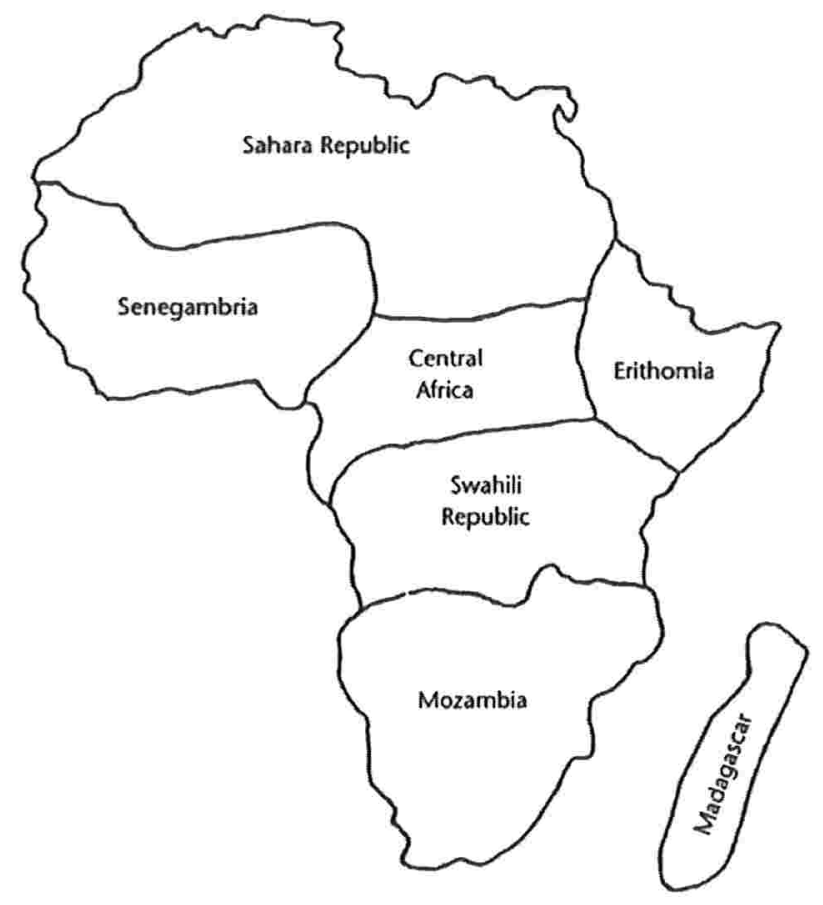

Fig. 1: Proposed new political map of Africa (Gakwandi 1996: 188)

Nollywood and Ugawood) following Fairclough (2006: 121) in contrast to topdown globalization that is driven by powerful, often external agents (World Bank, International Monetary Fund, Hollywood). Next, I shall use Nollywood, as the Nigerian motion picture industry is called, to illustrate continentalization.

\section{Nollywood and continentalization}

The Nigerian motion picture industry has been christened obviously in allusion to Hollywood and Bollywood, the only other two regional industries to surpass it in terms of volume and generated income. It is the second highest external revenue earner today for Nigeria after oil and gas. In 2007 alone, 1,588 films were approved by the Nigerian Film and Video Censorship Board. The statistics in Table 2 shows that indigenous languages are not marginalised by the industry.

The relevance of this to continentalization is the manner in which the industry has donned a transnational toga and developed into an African and African diaspora industry with considerable patronage in Kenya, Uganda, Tanzania among other hotspots. Okhai (2008) notes that: 
Table 2: Statistics from a randomly chosen month in 2007

\begin{tabular}{llrllllll}
\hline \multirow{2}{*}{ Month } & \multirow{2}{*}{ Ratings } & \multirow{2}{*}{ Total } & \multicolumn{5}{c}{ Language of production } \\
\cline { 4 - 8 } & & & & English Yoruba & Hausa Edo & Others \\
\hline \multirow{2}{*}{ May 2007 } & PG & 8 & 4 & 1 & 3 & - & - \\
& 12 & 1 & - & 1 & - & - & - \\
& 15 & 11 & 7 & 4 & - & - & - \\
& 18 & 157 & 65 & 67 & 13 & 11 & 1 (Efik) \\
\hline Total & 177 & & & & & & \\
\hline
\end{tabular}

Today American movies have lost their dominance. In most African homes, street side theatres, hotel rooms and television stations, Nollywood has taken over. Africa Magic the Trans-African movie channel is proof enough. There is a cultural neo-colonisation of the African continent by Nollywood films. People now speak Ibo words and Pidgin English in far-off places like South Africa as a result of this. It is now hip to shout Igwe!!! (Okhai 2008: 3)

Arguably, Nollywood in this sense facilitates Pan-Africanism by exploring the homogenizing tendencies of continentalization. However, within nation-state frameworks of analysis, this could be regarded as "neo-imperialism" or "neocolonialism". In relation to borderlands, boundary crossing between individual countries as sovereign units and between Anglophone and Francophone regions as cultural blocs raise issues of which languages (or varieties of language) have mobility and which don't (Blommaert 2008). A form of English rather than an indigenous African language is propped up by subtitling (cf. Simala 2003). Beyond the physical ethnolinguistic borderlands lie racial borderlands between homeland populations, their diasporas and other racial groups united by Nollywood. Wole Soyinka instantiates the location of the racial borderland in a presentation he gave at the FESTAC colloquium in 1977 titled "The scholar in African society" when he remarked:

So, to my black - spelt, presumably with a double $\mathrm{K}$ - to my black brother in the United States of America I say simply that your dilemma, as a hysterically sensitive people is the same as mine - neither of us has yet found a definition, so woefully trapped are we in their languages, and their alphabets. (Soyinka 1977: 46, my emphasis)

It would seem then that the proliferation of Nollywood on the African continent and the African diaspora generally is indeed a linguistic coup d'etat because rather than Swahili, the beneficiary of continentalization is (a variety of) English. This is in sharp contrast to the tenor in Soyinka's (1977) appeal: 
We exhort all writers to apply every strategy; individually and collectively on both national and continental levels to promote the use and the enrichment of Swahili for the present and future needs of the continent. In this connection, we have resolved that the proposed African Co-operative Publishing House shall adopt the policy of translating every work it publishes into Swahili. We exhort all schools to accelerate this process by substituting the study of Swahili for the least viable subject on their curriculum such as European ballet, la Civilisation Française, English Social History, etc., etc. (Soyinka 1977: 49)

Soyinka had invoked the resolution at the 1975 Cairo conference of the All Africa Union of Teachers "that the continent of Africa adopt one common language and proposed a selection from Hausa, Arabic and Swahili". Three decades on, Ugandan producer Osman Matovu, commenting on the local motion picture industry, shed light on the continuing competition between African languages and former colonial languages when he observed that:

"Some people prefer local languages while others want English. Those who prefer local languages do buy our films while the English speaking elite with more money are instead full of criticism and don't value local productions," (Osman Matovu, reported in the article by Musinguzi, Bamaturaki (2007) 'Uganda: Pirates of the African Screen'). http://allafrica. com/stories/200710021063.html (Accessed February 28, 2014)

The point to reiterate here though is that globalization's or continentalization's forces are remotely at play in the assignment of capital to all languages. In other words, the linguistic market is subject to influences from beyond the local. The Nollywood-Ugawood collaboration has extended to music with the production of a bilingual album with songs in Luganda and Pidgin English. This defies the conventional patterns of language contact in contiguous territories. If the pattern proliferates, the resulting conceptual borderland would need to be explained by recourse to the history of Nollywood's continentalization. David Kaiza writing in The East African of Nairobi (4 February 2008) stretches Nollywood's capacity beyond mere continental identity to encompass Black racial identity and says:

\footnotetext{
It is mostly low budget, low quality work, making full use of the sensational themes - sex, crime, drugs and broken homes.... But it is what it is doing to building the black self-image that makes Nollywood perhaps the most powerful cultural project since the coming of Christianity. The black face becomes the action face; the hero with the rounded life at the centre of a completely black world. This contrasts sharply with the condescending treatment of black people in Hollywood. Obviously, the millions who tune in to Nollywood daily feel something they don't get in Hollywood. (Kaiza 2008)
}

These cultural crossings blur intra-continental boundaries and reset the modes of differentiation with foreign products. 


\section{Conclusion}

In the foregoing, I have attempted to theorize border as a phenomenon in relation to language and globalization. Rather than the sense of globalization as a homogenizing social process, the perception of borders as zones of continuity allows us to explore the alternative view of globalization as a compression of time and space. The bisection of ethnicities by African nation-state boundaries already created a framework for the continuation of languages and language practices beyond borders. Thus, division into Anglophone and Francophone countries did not automatically exclude practices and products from either sphere to penetrate and permeate the other. These resources and practices continue to flow either through the shared bisected language or in translation into superimposed colonial language facilitated by the dynamics of media and cultural globalization.

I have also, with specific focus on the African context, proposed continentalization as a bottom-up African approach to globalization in which the observable direction of flow is South-South. In other words, the compression of time and space occurs within Africa through social processes that identify and showcase de-ethnicized and de-nationed practices. I have used the adoption, consumption and adaptation of Nollywood films across Africa and the observable consequences of these in language practice to illustrate how the model works. It is significant that Nollywood and other popular culture products seem to be succeeding in pushing the Pan-Africanism agenda, a task in which the political elite seem to have failed.

\section{References}

Appadurai, Arjun. 1996. Modernity at large: cultural dimensions of globalization. Minneapolis: University of Minnesota Press.

Asiwaju, A. I. 1985. Partitioned Africans. Lagos: University of Lagos Press.

Asiwaju, Anthony I. \& Peter O. Adeniyi. 1989. Borderlands in Africa: A multidisciplinary and comparative focus on Nigeria and West Africa. Lagos: University of Lagos Press.

Blommaert, J. 2003. Commentary: A sociolinguistics of globalization. Journal of Sociolinguistics 7(4) [Special issue: Sociolinguistics and Globalization]. 607-623.

Blommaert, J. 2006. Sociolinguistics scales. Working Papers in Urban Language and Literacies 37. http://www.kcl.ac.uk/sspp/departments/education/research/ldc/publications/ workingpapers/37.pdf (accessed 14 January 2014).

Blommaert, J. 2008. Grassroots literacy: writing, identity and voice in Central Africa. London \& New York: Routledge.

Coupland, N. 2003. Introduction. Journal of Sociolinguistics 7(4) [Special issue: Sociolinguistics and Globalization]. 465-472. 
Fairclough, N. 2006. Language and globalization. London: Routledge.

Gakwandi, A. S. 1996. Towards a new political map of Afric. In T. Abdul-Raheem (ed.), Pan-Africanism: Politics, economy and social change in the twenty-first century, 181-190. London: Pluto Press.

Giddens, A. 1990. The consequences of modernity. Cambridge: Polity.

Gordon, Raymond G., Jr. (ed.). 2005. Ethnologue: Languages of the World, 15th edn. Dallas, Texas: SIL International. http://www.ethnologue.com/15 (accessed 14 January 2014).

Hensey, Frederick. 1972. The sociolinguistics of the Brazilian-Uruguayan border. The Hague: Mouton.

Hensey, Frederick. 1982. Spanish, Portuguese and fronterico: languages in contact in Northern Uruguay. International Journal of the Sociology of Language 34. 9-23.

Kaiza, David. 2008. 'Africa: The New Black Self-Image'. East African. http://allafrica.com/ stories/200802041216.html (accessed 28 February 2014).

Kerswill, P. 2006. Migration and language. In Klaus Mattheier, Ulrich Ammon \& Peter Trudgill (eds.), Sociolinguistics/Soziolinguistik. An international handbook of the science of language and society, Vol. 3, 2271-2284. Berlin \& New York: De Gruyter.

Martinez, G. 2009. Narrative sociolinguistic identities along the border. Paper presented at the CRONEM Conference, University of Surrey, Guildford.

Mazrui, A. A. 2005. Pan-Africanism and the intellectuals: rise, decline and revival. In T. Mkandawire (ed.), African intellectuals: rethinking politics, language, gender and development, 56-77. London: Zed Books.

Mazrui, A. A. \& A. M. Mazrui. 1998. The power of Babel: language and governance in the South African experience. Oxford: James Currey.

Meinhof, U. \& D. Galasinski (in collaboration with the European Border Identities Consortium). 2000. Border discourse: changing identities, changing nations, changing stories in European border communities: a state of the art report. http://cordis.europa.eu/ documents/documentlibrary/90834341EN6.pdf (accessed 20 June 2012).

Momoh, C. S. 1989. A critique of borderland theories. In A. I. Asiwaju \& P. O. Adeniyi (eds.), Borderlands in Africa: A multidisciplinary and comparative focus on Nigeria and West Africa. Lagos: University of Lagos Press.

Okhai, V. 2008. Emerging talents: Nollywood and the future of African Cinema. Paper presented at the BOB TV 5th African Film and Television Programmes Expo, Sheraton Hotel and Towers, Abuja, March 11.

Omoniyi, T. 2000. Island identities: A theoretical framework. International Journal of the Sociology of Language 143. [Special issue: Islands and identity in sociolinguistics: Hong Kong, Singapore and Taiwan]. 1-13.

Omoniyi, T. 2004. The sociolinguistics of borderlands: two nations, one people. New Jersey: Africa World Press.

Omoniyi, T. 2007. Outsourcing and migrational anxieties in discourse perspectives. In Suman Gupta \& Tope Omoniyi (eds.), Cultures of economic migration: international perspectives, 37-51. London: Ashgate.

Omoniyi, T. 2010. The sociolinguistics of colonization: A language shift perspective. Sociolinguistic Studies 3(3). [Special issue: Language shift in West Africa]. 307-328.

Omoniyi, T. 2013. Constructing local and global in the e-borderland. In R. Rubdy \& L. Alsagoff (eds.), The global-local interface, language choice and Hybridity. Bristol: Multilingual Matters. 
Omoniyi, T. \& O. Salami. 2004. Identity constructs in a contested borderland: the Bakassi Peninsula. In Duro Oni, Suman Gupta, Tope Omoniyi, Efurosibina Adegbija \& Segun Awonusi (eds.), Nigeria in the age of globalization: contemporary discourses and texts, 171-193. Lagos: Centre for Black and African Arts and Culture.

Passarelli, A. \& D. Peschke. 2006. Resettlement: protecting refugees sharing responsibility. Brussels: Churches' Commission for Migrants in Europe/CCME. http://www.ccme.be/ fileadmin/filer/ccme/20_Areas_of_Work/01_Refugee_Protection/2006-10-19_CCME_ Publ_-_Resettlement_-_Protecting_Refugees_Sharing_Responsibility.pdf (accessed 14 January 2014).

Prescott, J. R. 1965. The geography of frontiers and boundaries. London: Hutchinson University Library.

Robertson, R. 1992. Globalization. London: Sage.

Simala, K. I. 2003. Pan-Africanism and the language question: re-reading African cultural and intellectual history. Dakar: Council for the Development of Social Science Research in Africa.

Strassoldo, Raimondo. 1973. Frontier regions: an analytical study. Strasbourg: Council of Europe.

Soyinka, Wole. 1977. "The Scholar in African Society," in A. U. Iwara and E. Mveng, eds., Second World Black and African Festival of the Arts and Culture: Colloquium on Black Civilization and Education. Colloquium Proceedings, Volume 1, Lagos: Federal Government of Nigeria, 44-53.

Waters, M. 2001. Globalization, 2nd edn. London: Routledge.

Wa Thiong'o, N. 2005. Europhone or African memory: the challenge of the pan-Africanist intellectual in the era of globalization. In T. Mkandawire (ed.), African intellectuals: rethinking politics, language, gender and development, 155-164. London: Zed Books. 